\title{
Lines from afar - and a new line-up
}

\author{
Virman Man
}

Published online: 16 February 2011

(C) Springer Science+Business Media B.V. 2011

The starting point of this edition of the International Review of Education is provided by two thought-provoking articles which grapple with pivotal themes in lifelong learning. Yahui Su engages with the notion of the learning society - a term which these days is in frequent use, although interpreted in widely different ways. For $\mathrm{Su}$, a learning society is typified by having learning as its central concern rather than any derivative characteristic (such as greater democratic participation or a higher standard of living, for example). Learning should be pursued as an end in itself, and not regarded simply as a vehicle for achieving economic or civic goals. Far too often in the literature and policy discourse, Su points out, the inherent value of learning is either not touched upon or given only cursory treatment.

The focus changes from learning to education in Leah K. McMillan's comparison between human rights and developmentalist conceptualisations of education. In one case, education is championed as an inalienable human right; in the other, it is seen as a necessary part of the development of individuals and their societies. As human rights-based approaches to development have gained the ascendancy, the trend has been that the two conceptualisations have somewhat coalesced. McMillan argues that the result - certainly as far as primary education is concerned - has been an over-emphasis on the numerical fulfilment of the right to education (through ensuring high enrolment rates) with far less attention devoted to the purpose, content or quality of education.

It can be assumed that these issues are of interest to aid agencies and sponsors of international development assistance to primary education, and that they would have a strong wish to gauge the impact of their financial and technical support. However, David W. Chapman and Audrey Schuh Moore, examining the findings of nine meta-studies on the effectiveness of such support for the development of education systems, find that most of these evaluations concentrate more on assessing

V. Man $(\bowtie)$

UNESCO Institute for Lifelong Learning, Hamburg, Germany

e-mail: v.man@unesco.org 
inputs than outputs. They observe that often there is a paucity of evidence and an absence of simple baseline data. Furthermore, the evaluations offer little guidance on identifying promising strategies for future projects. There are some salutary lessons here for the design of monitoring and evaluation strategies, including the criteria used to measure success (however that may be defined).

Tarek Mostafa considers how inequalities of student background, peer effects and school characteristics play out on performance scores in five OECD countries. The main tenet here is an intuitive one: namely that economic, social and cultural backgrounds have a major effect on student performance. However, the author suggests, there are likely to be variations caused indirectly by the social stratification of pupils between schools and by differences in school resource levels and staff culture. The results from Mostafa's multiple regression analysis lend credence to the view that the degree of heterogeneity among schools can greatly distort or entrench patterns of inequality. As countries' formal educational systems differ in the level of state management and in the extent of pupil selection, so too will the policy implications for tackling educational inequality.

The improvement of educational outcomes in secondary schools is the subject of the article by Boaz Shulruf. It is a commonly-held belief that school-organised extra-curricular activities can be significant developmental environments for adolescents, in which they can pursue an interest or commitment, learn to manage time and gain access to wider social networks. Shulruf's interrogation of the literature seeks to establish whether such activities indeed have a positive effect on academic achievement, school retention and pupil self-concept. He investigates what it is in particular about participation in extra-curricular activity that brings about positive outcomes and why.

The quality of teaching staff is a key factor for educational success, and the next two articles address teacher training under very different circumstances. Manhong Lai conducted an in-depth study of a secondary school in China to look at teacher development in the context of curriculum reform. The change from a teachercentred to a student-centred approach in teaching presented major challenges, with teachers finding that preparation for the new curriculum approach was inadequate in terms of time and training. Older teachers especially felt that they were left to work out for themselves how to adapt. In the school studied by Lai, school-based teacher development activities tended to be top-down and mandatory rather than a collective process of reflection and exchange. Much depended on the leadership style of departmental heads.

Steve Alsop, Patricia Ames, Graciela Cordero Arroyo and Don Dippo present examples of collaborative teacher education from a five-year international education development programme, set in a rural district of northern Peru. Here the teachers were each required to make a specific educational intervention, working not only with teacher educators from three different countries (the authors), but also with the pupils and their communities. The article reports on the powerful effect that projects like this can have on the teacher participants undergoing training. In this case the teachers were able to generate their own interpretations of action, theory and research, leading the researchers to question their own methodology and pedagogical approach. 
On a related subject, Laura M. Crothers, Gibbs Y. Kanyongo, Jered B. Kolbert, John Lipinski, Steven P. Kachmar and Gary D. Koch contrast levels and frequency of job stress between teachers from locations in the United States and Zimbabwe. The key dimension which they investigate is the degree of control that teachers feel they have over their working environment. American teachers, they find, are more likely than their Zimbabwean counterparts to experience stress if they are unable to control external factors. The authors tentatively suggest that this may reflect a more individualistic culture in teachers in the United States.

Turning to materials used by teachers, Fatoş Silman and Mehmet Çaglar give an appraisal of citizenship education in Cyprus. What educational input can be made in the context of an island which is divided into two distinct cultural blocs which have strong cultural and political ties to the countries of their mainland states? The authors examined school textbooks used in Greek- and Turkish-speaking schools, and argue that to promote greater understanding between these communities there should be concerted attempts made to produce materials indigenously rather than use texts prepared in Greece and Turkey.

Tolerance and cultural acceptance flow as sub-themes in the article by Adelhak Qribi, Amélie Courtinat and Yves Prêteur. They consider how young people of North African immigrant descent in France express their identity. The authors look at factors that might influence the extent of assimilation into or differentiation from wider French society, such as success in schooling, religious and family values, and parents' level of education. By means of a multivariate analysis they are able to derive four broad profiles of identity, to each of whom a specific educational strategy would be applicable.

The last article in this edition turns to a key topic - literacy. Brij Kothari and Tathagata Bandyopadhyay explore the disjuncture between actual reading skills and literacy rates as reported in India's national census surveys. Partly, the authors claim, this is due to the self-reporting methodology adopted in such surveys. Reading tests are more likely to give a realistic picture, though the costs of conducting them on the scale required are prohibitive. The reading tests administered by the authors in sample populations from four Indian states reveal that there is no room for any complacency that might be derived from the national survey figures. Although the authors recognise that their results cannot be extrapolated nationally, there are clear policy warnings to be heeded.

This year, as in the past, enormous thanks are to be accorded to the IRE's Editorial Board, Consulting Editors and reviewers, whose support and active involvement have contributed so greatly to the journal. As we pass into 2011, we say a fond farewell and extend our gratitude to Editorial Board members who have given such valuable input and continuity over the years: Professor Christel Adick, Professor Birgit Brock-Utne, Françoise Caillods, Professor Steven J. Klees and Professor Michael Omolewa. To paraphrase Oscar Wilde, to lose one Editorial Board member may be regarded as a misfortune; to lose five looks like carelessness. We greet their successors, Professor Mark Bray, Professor Vandra Masemann, Gugulethu Ndbele, Professor Norbert Nikièma and Dr Zhang Min Xuan, and look forward to working with them. At the Editorial Office we welcome Maya Kiesselbach as Assistant Editor and Roselyne Höner as Editorial Secretary. 